\title{
Teenage Pregnancy And its Outcome Tale of The Toll - An Institutional Study from South India
}

\author{
Sajana Gogineni ${ }^{1}$,A. Ramadevi ${ }^{2}$,Gayathri $\mathrm{KB}^{3}$, Ravali Boppana ${ }^{4}$,Vishnu Santhi ${ }^{5}$ \\ 1(Professor \& Head, Department of OBGYN, Dr. Pinnamaneni Siddhartha Institute of Medical Sciences \& \\ Medical Sciences \& Research Foundation, Chinoutpalli, Gannavaram, Krishna Dt, AP) \\ 2(Asst. Professor, Department of OBGYN, Dr. Pinnamaneni Siddhartha Institute of Medical Sciences \& \\ Medical Sciences \& Research Foundation, Chinoutpalli, Gannavaram, Krishna Dt, AP) \\ 3(Assoc. Professor, Department of OBGYN, Dr. Pinnamaneni Siddhartha Institute of Medical Sciences \& \\ Medical Sciences \& Research Foundation, Chinoutpalli, Gannavaram, Krishna Dt, AP) \\ 4(Postgraduate, Department of OBGYN, Dr. Pinnamaneni Siddhartha Institute of Medical Sciences \& Medical \\ Sciences \& Research Foundation, Chinoutpalli, Gannavaram, Krishna Dt, AP) \\ 1(Senior Resident, Department of OBGYN, Dr. Pinnamaneni Siddhartha Institute of Medical Sciences \& \\ Medical Sciences \& Research Foundation, Chinoutpalli, Gannavaram, Krishna Dt, AP)
}

\begin{abstract}
:
Background: Teenage pregnancy (TP) is an important social and public health burden. WHO defines TP as pregnancy in an adolescent, aged between 10 and 19 years. About 16 million women, 15-19 years old give birth each year amounting to $11 \%$ of all births worldwide. In developed countries majority of teenage pregnancies occur to unmarried girls unlike developing countries. In India, teenage pregnancies are observed at a higher rate due to early marriage.

Aims \& objectives: Study the incidence of Teenage Pregnancies (TP) in our institute, quantify the Incidence of maternal medical and obstetric complications in TP, enumerate the fetal complications in TP Methods \& Materials: A retrospective observational study from the deliveries conducted in our institute between Sep'2015 and Nov'2016 were analyzed and evaluated

Results and conclusions: TP accounts to 24.7\%of total deliveries observed between Sep 2015 and Nov 2016.Teenage pregnancies are associated with more incidence of abortions (10\%), medical complications like HTN, pre Eclampsia, hypothyroidism, DM (9\%), increased risk of anemia (30\%), assisted vaginal deliveries (13\%) and increased LSCS rates (27\%) Risk of preterm delivery were identified to be similar in both groups. This study concludes that teenage pregnant women are more prone for developing anemia, pre-eclampsia during pregnancy, TP poses significant risk of adding further financial burden to family and society.
\end{abstract}

Keywords: Teenage pregnancy, Maternal and fetal outcomes

\section{Introduction}

Teenage pregnancy (TP) is an important social and public health burden. WHO defines TP as pregnancy in an adolescent girls aged between 10 and 19 years. About 16 million women, 15-19 years old give birth each year amounting to $11 \%$ of all births worldwide. Ninety-five percent of these births occur in low and middle-income countries. Although adolescents aged 10-19 years' account for $11 \%$ of all births worldwide, they account for $23 \%$ of the overall burden of disease. TP is associated with many medical complications and fetal problems like IUGR, low birth weight. Around 3,03,000 adolescent mothers died due to pregnancy and child birth related complications in 2015 (WHO)

According to UNICEF, worldwide every 5th child is born to teenage mother. Worldwide 13 million births each year occur to girls younger than 19 years. The incidence of teenage pregnancies varies dramatically between the different countries. Approximately $90 \%$ of the teenage births occur in developing countries. Nevertheless, there is also a significant variation in teenage pregnancy and birth rates between developed countries, although teenage pregnancy and birth rates of developed countries are significantly lower than that of developing countries. In large regions of the world, age at marriage has traditionally been low. Fecundity rates are higher in adolescence girls. Adverse Maternal outcomes of teenage pregnancy includes Preterm labor, anemia, Hypertensive Disorders of Pregnancy, abortion and high rate of Cesarean Sections for cephalopelvic disproportion and fetal distress. Adverse fetal outcomes include preterm births, Low Birth Weight infants, Respiratory Distress Syndrome Teenage pregnancies are problematic because complications due to pregnancy and childbirth. High maternal mortality in adolescence pregnancy is seen in developing countries.

The present study aims to find out the incidence and to evaluate the various complications associated with teenage pregnancy. 


\section{Materials And Methods}

A retrospective observational study from the deliveries conducted in our institute between Sep'2015 and Nov'2016 were analyzed and evaluated. Institute ethical committee has approved this study. All pregnant females admitted to the Hospital in the age group of 13-19 years during the study period were included and all pregnant females equal to or more than 20 years admitted to the Hospital during the same period were excluded from the study. The required details were collected from hospital records.

\section{Result S And Observation}

In the present study among the total 1491 deliveries, 369 deliveries comprised of teenage pregnancy,

1. TP accounts to $24.7 \%$ of total deliveries observed over a period of one year i.e. between Sep 2015 and Nov 2016.

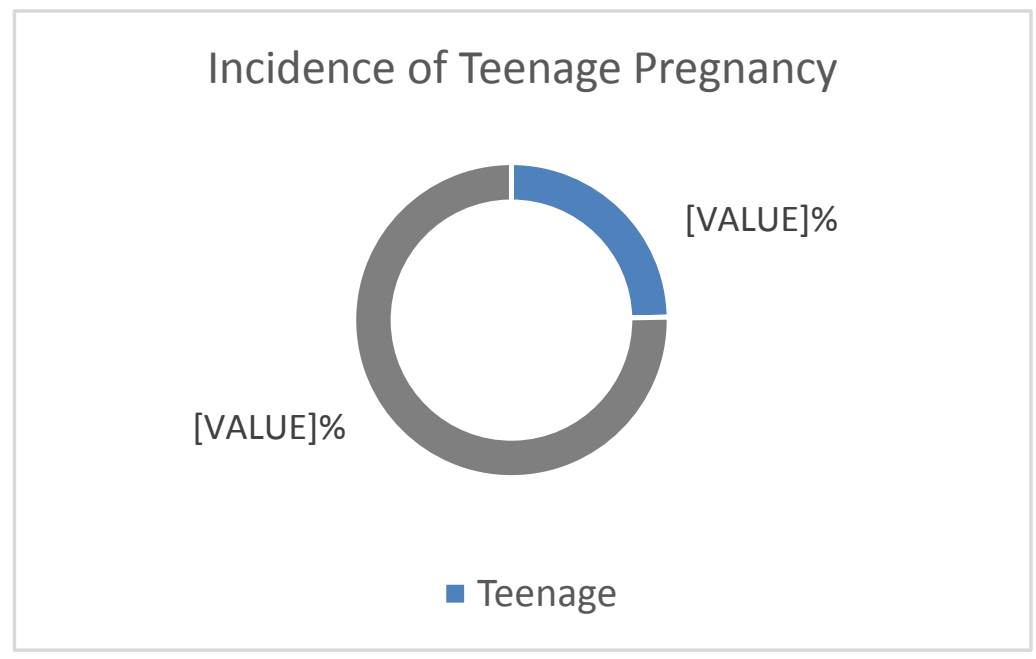

2. Teenage pregnancy is most commonly associated with anemia, this is due to increased demand of hemoglobin for their own body demands. In teenage mothers of developing countries like India, mostly due to low socio economic status associated with improper nutrition intake. In this present study, low levels of $\mathrm{Hb}$ was observed in $30 \%$ of the study population.

\section{3.}

\section{$\mathrm{Hb}$ Values in Teenage Pregnancy}

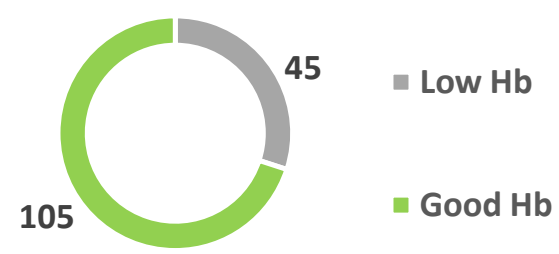

4. Among the teenage pregnancies during the first trimester the most common complication is abortions and in the present study the study cases are associated with more incidence of abortions (10\%) all are spontaneous in onset.

5. Within Teenage pregnancies all the associated medical complications are aggravated and $9 \%$ of the subjects of the study are associated with medical conditions like (HTN, Eclampsia, Hypo-Thyroidism, $\mathrm{DM})$. 


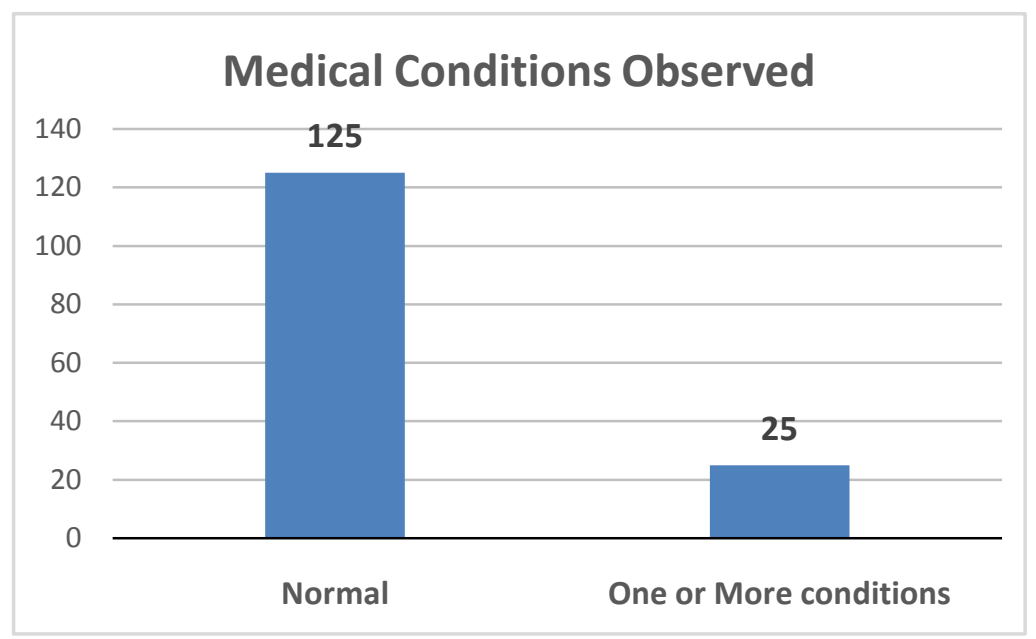

6. Out of the observed Teenage pregnancies, the most common outcome is normal delivery followed by csections, assisted deliveries and among them 9 are associated with pre-term deliveries, (12) Ventouse Assisted, (9) Forceps Assisted, (48) Sections and (68) NVD/FTVD.

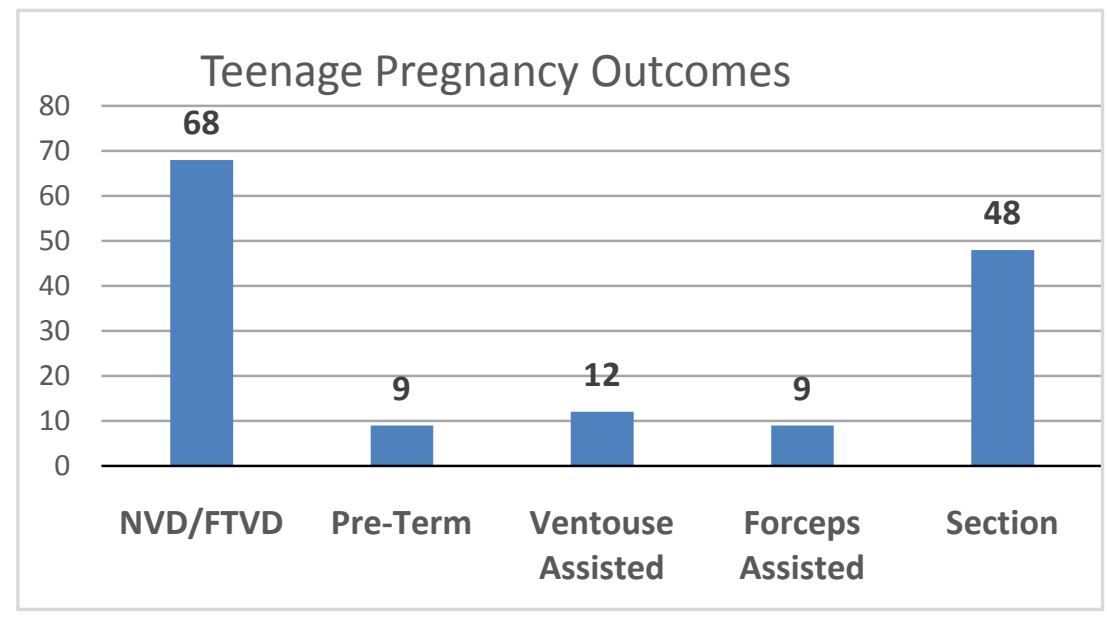

7. Only in 7\% of the teenage pregnancy cases, elective LSCS was taken up. Emergency LSCS were more prominent in Teenage pregnancies, with an incidence rate of $27 \%$.

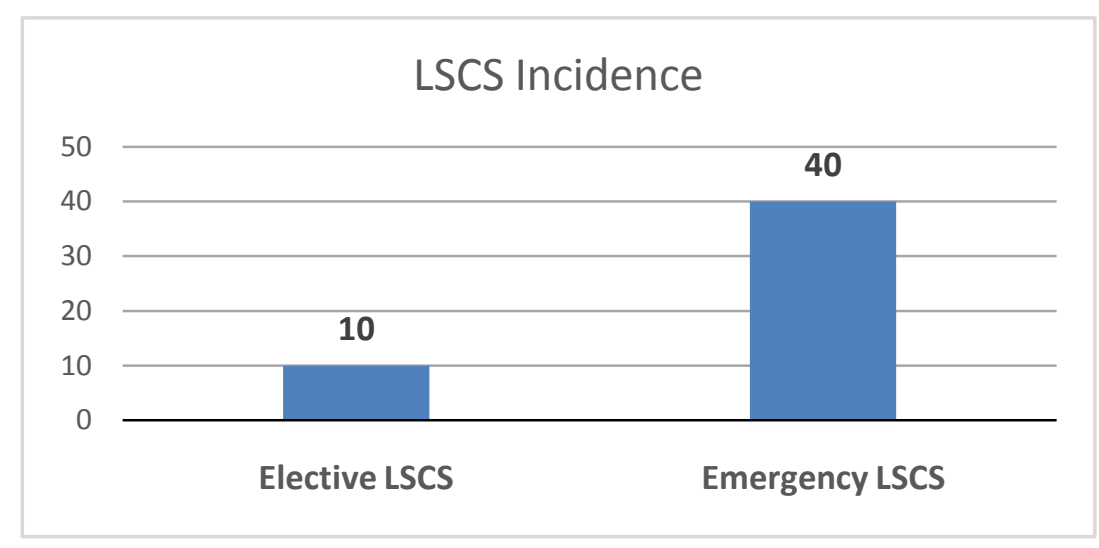

7. Majority of the babies born out of such pregnancies are healthy. The most common adverse fetal outcome in the study was low birth weight and within the observed cases, 62 cases of less than normal birth weight were observed. Within these cases $8 \%$ of Extremely Low $(<1.5 \mathrm{KG}), 16 \%$ of Very Low $(<2 \mathrm{KG}), 75 \%$ of $\operatorname{low}(<2.5 \mathrm{KG})$ 


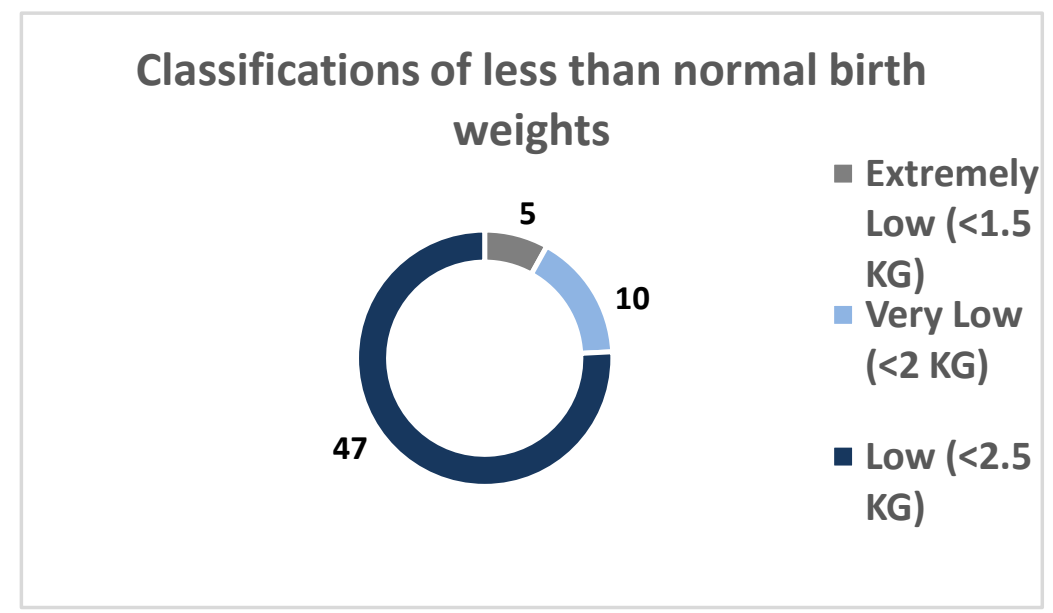

IV. Outcome Comparison With Other Studies

Incidence of teenage pregnancy in this study is $24.7 \%$.Comparision with incidences of other Indian studies are shown in the following table

\begin{tabular}{|l|l|l|l|}
\hline & Present Study & $\begin{array}{l}\text { GazalaYasmin } \\
\text { et al. }\end{array}$ & $\begin{array}{l}\text { Pikee } \\
\text { Saxena et al. }\end{array}$ \\
\hline Incidence & $24.7 \%$ & $5.1 \%$ & $19 \%$ \\
\hline Preterm labour & $6 \%$ & $27.45 \%$ & $29.9 \%$ \\
\hline Anemia & $30 \%$ & $8.12 \%$ & $52 \%$ \\
\hline IUGR & $9.3 \%$ & $8.4 \%$ & $5.5 \%$ \\
\hline LBW & $41.6 \%$ & $16.86 \%$ & $33.9 \%$ \\
\hline
\end{tabular}

\section{Discussion}

Teenage pregnancy is an important social and health problem, accounting for approximately $10 \%$ of all pregnancies worldwide.

- Teenage pregnancy is most commonly associated with Risks of low birth weight, premature labour, anemia $\&$ pre-eclampsia.

- The incidence of teenage pregnancies in our institution is around $24.7 \%$.

- According to a study by Shagufta et al. ${ }^{3}$ the prevalence of teenage pregnancy is $11 \%$

- According to another study conducted in Bhopal, Teenage pregnancy comprised 5.1\% of the total Obstetric admissions.

- This difference might be a result of difference in the area of study, as the level of education, socioeconomic status, and prenatal care vary according to the area.

- According to Tripati etal study the percentage of anemia is around $20 \%$ and in this study it is around $30 \%$

- In our institute there is an increased incidence of anemia not only in teenagers but also in adult women. This low hemoglobin level is due to many factors including poor diet, improper sanitation, poverty and lack of education about iron supplements during pregnancy.

- Only 9\% of TPs observed in this study were associated with medical complications. Which was actually less when compared to a study by shagufta etal.(18.4\%), This difference may be due to difference in the location of the hospital, being a city cited tertiary hospital they received only the high risk cases from the rural areas of this teenage group as normal cases are taken care by the local birth attendants. Inadequate or lack of prenatal care is most common attributable factor for pre-eclampsia. It is also hypothesized that underdeveloped endocrinal system may be cause of hypertensive disorders of pregnancy.

- Abortions are around $10 \%$ which is same when compared with shaguffta etal study. 
- Preterm deliveries are around $6 \%$ where as it varies in different studies from $(10 \%-20 \%)^{3,6,12}$. The increased risk of preterm labor has been attributed to biologic immaturity of the uterus or to shortness of the cervix, with subsequent increased risk of ascending infection. Psychological instability of young mothers also adds to the risk of preterm delivery.

- The incidence of IUFD, one of the neonatal complications, found to be significantly higher in the teenage pregnancy according to a study by Mahmoud Edessy et al. ${ }^{6}$

- No intrauterine deaths are noted in our institution in teenage pregnancy.

- In this study the need for assisted delivery is more and this may be due to the more chance of preterm deliveries.

- These findings were reported by other studies who suggested that TP was associated with increased incidence of assisted delivery ${ }^{7,8}$ and increased incidence of spontaneous delivery. ${ }^{9,10}$

\section{Conclusion}

- The present study aimed to evaluate the outcomes and complications of teenage pregnancy.

- This study concludes that teenage pregnant women are more prone for developing anemia, pre-eclampsia during pregnancy. Teenage pregnancies also face a significant risk of leading into LSCS, due to increased chance of CPD, as these mothers are still in their musculoskeletal phase of growth in life.

- IUGR and Low Birth Weight were major adverse fetal outcomes, due to increased medical complications in mother like HTN, leading to decreased uteroplacental flow and nutritional deficiency due to increased demand in pregnancy.

- TP should be considered as high risk pregnancy by every health care provider, so that adequate counselling can be given in initial part of pregnancy regarding signs and symptoms of various complications and emphasis over proper antenatal visits and nutrition is given

- Education of the female child and her family can play a significant role in delaying marriage, delay in childbearing, which protects young girl from being exposed to the various complications of teenage pregnancy.

\section{References}

[1]. World Health Organization, United Nations population fund: Married adolescents: no place of safety. Geneva: WHO-UNFPA; 2006.

[2]. Teenage pregnancy - its impact on maternal and fetal outcome international journal of scientific study | March $2014 \mid$ Vol $1 \mid$ Issue 6

[3]. Maternal and fetal outcome in Teenage pregnancy SHAGUFTA TABASSUM. SHUMAILA TABASSUM P J M H S Vol. 8, NO. 3, JUL - SEP 2014

[4]. Mayor S. Pregnancy and childbirth are leading causes of death in teenage girls in developing countries BMJ. 2004;328:1152.

[5]. Adolescent pregnancy- Issues in adolescent health and development, WHO discussion papers on adolescence. WHO, 2004 Pg 86.

[6]. Mahmoud Edessy, Manal Gaber, and Abdel-Rahman Maher. Teenage pregnancy and fetal outcome. American Journal of Research Communication, 2014, 2(10): 169-175

[7]. Bacci A, Manhica GM, Machungo F, Bugalho A, Cuttini M(1993) Outcome of teenage pregnancies in Maputo, Mozam-bique. Int J Gynaecol Obstet 40(1):19-23

[8]. Konje JC, Palmer A, Wastson A, Hay DM, Imrie A, Ewings P(1992) Early teenage pregnancies in Hull. BJOG 99(12):969-973

[9]. Buitendijk SE, Van Enk A, Oosterhout R, Ris M (1993) Obstetrical outcome in teenage pregnancies in the Netherlands.Ned Tijdschr Geneeskd 137(49):2536-2540

[10]. Ziadeh S (2001) Obstetric outcome of teenage pregnancies in North Jordan. Arch Gynecol Obstet 265:26-29

[11]. Saxena P, Salhan S, Chatopadhyay B, Kohli MPS, Nandan D and Adhish SV. Obstetrics and perinatal outcome of teenage and older primig ravidas - A retrospective analysis. Health and Population: Perspectives and Issues. 2001; 33(1):16-22.

[12]. Outcome of teenage pregnancy, Tripathi M, Sherchan A Journal of Universal College of Medical Sciences (2014) Vol.02 No.02 Issue

[13]. UNICEF. A league table of teenage births in rich nations. Innocenti Research Centre Florence, Italy. 2001, Dubashi SS, Wani R. Teenage pregnancy. Bombay $\mathrm{H}$ 